\title{
Tourists' Perception of International Air Travel's Impact on the Global Climate and Potential Climate Change Policies
}

\author{
Susanne Becken \\ Lincoln University, New Zealand
}

\begin{abstract}
Tourism's increasing contribution to climate change, especially through the use of air travel, is now acknowledged. This study seeks to explore tourists' knowledge and awareness of aviation's impact on the climate, their sense of personal responsibility and their reactions to specific climate change policies. A focus group approach - informed by interviews with international tourists leaving New Zealand - was chosen to involve tourists in discussing climate change and travel. In the focus groups, three policy options were discussed: voluntary initiatives, a global air travel charge and a per capita carbon budget. The global air travel tax emerged as a realistic compromise between restricting travel and achieving emissions reduction. When discussing individual responsibility for greenhouse gas (GHG) emissions, tourists distinguished between their travel and their everyday life, where responsibility for mitigation was perceived to be greater. The value of freedom to travel is firmly established in the minds of many tourists and limiting travel is considered unacceptable by the (hyper) mobile tourists who participated in this research. Only major societal changes to bring about behavioural change seem likely to reduce air travel's contribution to climate change.
\end{abstract}

doi: $10.2167 / j o s t 710.0$

Keywords: air travel, tourism, carbon tax, carbon budget, voluntary initiatives

\section{Introduction}

International aviation is an important contributor to global climate change via its fossil fuel consumption and resulting greenhouse gas (GHG) emissions. Globally, aviation contributes between 3.5\% (Penner et al., 1999) and 4.6\% (Gössling \& Peeters, 2007) to the total anthropogenic GHG emissions, and it is expected that this share will grow considerably in the future. ${ }^{1}$ GHG emissions from international air travel are not included in nations' compulsory reduction targets ${ }^{2}$ as outlined in the Kyoto Protocol. There is, therefore, no binding need for countries to address these emissions. Emission reduction potentials through new aircraft engine technologies could be in the order of $20 \%$ by 2050 (Penner et al., 1999), and further gains are expected from improved airframes, weight reductions and better air transport management. More recently, market-based instruments, such as voluntary agreements, emission trading (discussed in the European Union) and emission taxes or charges, have also been discussed (International Civil Aviation Organisation, 2004). But the ongoing growth of air travel could cancel out these technical and fiscal measures (Gössling \& Peeters, 2007). 
Market-based policies for aviation could be targeted at reducing demand, providing incentives for the airline industry to reduce emissions or generating tax revenue for the government that may or may not be used for climate-related mitigation or adaptation activities. Increased airfares would probably result in decrease in demand, especially among leisure travellers (Gillen et al., 2005). A recent meta-analysis of air travel price-elasticity studies showed that long distance travel is less price-elastic (i.e. sensitive) than short distance travel, possibly because the choices and possibilities for substitution are fewer (Brons et al., 2002). Brons et al. also found that air travellers have become less pricesensitive over the last two decades, maybe reflecting the increasing use of air travel by the wider society. It also seemed that travellers are less likely to decrease demand immediately, but will react more sensitively in the long run when they have had time to adjust to the new prices (Brons et al., 2002).

The implementation of policies is likely to be more successful if some input into these is sought from those who would be affected, i.e. air travellers (Kasemir et al., 2000a, 2004b). Relying solely on expert knowledge entails the risk that important factors that concern the public might be overlooked. However, little research has been undertaken to investigate whether tourists are aware of their air travel impacts and whether they are willing to mitigate those impacts. Earlier research by Becken (2004) suggested that tourists to New Zealand were moderately educated about climate change, but similarly to other members of the lay public, tourists tended to confuse climate change with other environmental problems (see also Kasemir et al., 2000a; Lorenzoni \& Pidgeon, 2005; McDaniels et al., 1996; Stoll-Kleemann et al., 2001). Common perceptions by lay people had been depicted in an earlier study in the United States by Kempton (1991), who identified four dimensions to people's interpretation of climate change. First, climate change was commonly linked with the better-known concept of stratospheric ozone depletion. Second, GHGs were confused with other tropospheric air pollutants; third, there was confusion about the generally known principle of photosynthesis, i.e. the absorption of carbon dioxide by plants, including a perceived risk of exhausting all the oxygen in the atmosphere, for example, as a result of deforestation. And finally, people seemed to relate to climate change through personal experience with weather, for example, an exceptionally hot summer. Kempton summarised that the general public will continue to distort the facts until climate change has been established as a concept in its own right, significantly different from the four interpretations described earlier. More recent studies (e.g. European Commission, 2005; Henry, 2000) indicate that knowledge held by the general public has increased since Kempton's study.

It is believed that knowledge about certain environmental risks may increase awareness and ultimately encourage pro-environmental behaviour ( $\mathrm{O}^{\prime} \mathrm{Connor}$ et al., 1999). However, what people know about climate change is strongly influenced by its representation and the discourse that surrounds it. Since personal experience with the phenomenon is hardly existent, the media play an important role in filling this gap and thereby influencing the public's perception of climate change (Corbett et al., 2002). Climate change reporting by journalists often lacks accuracy, is subject to distortions and bias and tends to misrepresent the (scientific) uncertainty around climate change (Zehr, 2000). In relation to aviation and climate change, the discourse is produced largely by those involved in 
the aviation industry. Gössling and Peeters (2007) discuss some of the common discourse around air travel, for example, 'air travel is energy efficient' and 'air travel is economically important'. They conclude that the current discourse on air travel - and its failure to represent scientific understanding - constitutes a major impediment to behavioural changes by individuals.

Against the background of tourism's increasing contribution to climate change, this study seeks to explore tourists' knowledge and awareness of aviation's impact on the climate, their sense of personal responsibility and their reactions to specific climate change policies. The study is set in New Zealand; a destination that in terms of international tourism is totally dependent on international air services (Becken, 2002). New Zealand is often perceived as a 'clean and green' destination, and tourists here have been found to be open to discussions on the environmental impacts of their travel (Fairweather et al., 2005).

\section{Methodology}

The methodology comprised two steps. First, 63 international tourists leaving New Zealand were interviewed at Christchurch International Airport (separate report available from the author on request) to gain an initial understanding of tourists' knowledge and their preparedness to mitigate their impacts from air travel. In those interviews, a series of questions was formulated that covered tourists' knowledge of air travel impacts and their attitudes towards air travel, including green branding and active involvement in mitigation. Knowledge gained from those interviews informed the development of a focus group approach, which aimed to extract more detailed data on tourists' perceptions and attitudes. This paper presents the results of the focus group research.

\section{Focus group research}

Focus groups are increasingly employed in social science research, as they provide data and insights that would not be accessible when interviewing tourists individually (Weeden, 2005). Focus groups make explicit use of group interaction by encouraging participants to discuss their own and others' arguments and perceptions (Kitzinger \& Barbour, 1999). The typical size of a focus group is 5-10 participants (e.g. Goss \& Leinbach, 1996). A skilled facilitator provides the focus (e.g. by providing initial information) (Gibbs, 1997) and leads the discussion. Focus groups are useful to explore consensus on particular issues or policies; especially when there is a power discrepancy between lay people and decisionmakers (Morgan \& Kreuger, 1993). The focus group approach has been used before in climate change research as a tool to integrate lay people into activities that support policymaking (Stoll-Kleemann et al., 2001).

Focus groups do not represent natural discussions, and the viewpoints presented by participants are verbal self-reporting (i.e. hypothetical); hence real behaviour can only be inferred from participants' statements. Since participation in the focus group is usually voluntary, the sample is voluntary and may therefore represent those who are interested in a particular issue. The method of focus groups does not aim to generate data representative of a greater population, but seeks to enhance our understanding of a particular issue. As pointed out by 
Barbour (1995), focus groups can (indirectly) function as an educational forum and induce change among participants.

For the purpose of this focus group research, the New Zealand Youth Hostel Association (YHA) provided facilities and access to guests in their Christchurch and Wellington hostels. Each meeting was advertised in advance, and drinks and snack food were provided as an incentive to participate in the meetings. Five focus group meetings were held, each lasting between 1.5 and 2.5 hours and including between four and eight participants. The meeting was facilitated by one researcher and observed by a second researcher. In addition, the sessions were recorded on video and audio tapes. The software package 'QSR NVivo 2.0' was used for the analysis of the qualitative data.

Focus group participants received a brief introduction to climate change and how tourism relates to it, bearing in mind the difficult balance between providing sufficient context and information to research participants and not influencing people's thinking (O'Connor et al., 1999). Each meeting was structured into three phases: climate and travel quiz, role play and general discussion. The purpose of each section is further described as follows.

\section{Climate and travel quiz}

The purpose of the quiz was to frontload facts on climate change and tourism and to stimulate a discussion about the issue. The airport interviews had demonstrated that most tourists lack specific knowledge about climate change and need to be prompted to generate a useful discussion. A quiz was believed to provide a relaxed atmosphere, which was considered important given that participants were on holiday. The 20 questions covered the areas of tourism (e.g. which country is the most visited tourist destination), climate and climate change (e.g. which is the most abundant anthropogenic GHG) and air travel (e.g. how many tonnes of $\mathrm{CO}_{2}$ are emitted during a flight from London to Auckland). Questions were multiple-choice to help tourists discuss possible answers. Correct answers were rewarded by sweets.

\section{Role play}

Building on knowledge made available through the quiz, the facilitator explained that air travel was an increasingly important component of modern tourism and development, but that at the same time aviation contributes to global warming and so far no regulations are in place to manage GHG emissions from air travel. Participants were presented three different policy scenarios (to be implemented hypothetically in 2010) to address the situation. ${ }^{3}$

- Scenario I, 'Voluntary initiatives': both airlines and passengers engage voluntarily in initiatives that reduce emissions (e.g. carbon offsetting).

- Scenario II, 'Global air travel tax': emissions from aviation will be taxed and increase airfares by up to $20 \%$.

- Scenario III, 'Carbon budget': every global citizen has an annual budget of 3.5 tonnes of $\mathrm{CO}_{2}$ emissions; saving and emission trading is possible.

The scenarios were developed based on current policy discussions held among key agencies (e.g. ICAO, 2004), recent studies in the areas of emission trading (Wit et al., 2005), emission charges (e.g. Carlsson \& Hammar, 2002; 
Table 1 Roles chosen by tourists across the five focus groups

\begin{tabular}{||c|c||}
\hline Role & Count \\
\hline Tourist with high budget & 4 \\
\hline Tourist with low budget & 4 \\
\hline President of World Wildlife Fund for Nature (WWF) & 4 \\
\hline CEO of Touristik Union International (TUI) & 4 \\
\hline CEO of Ryanair (European low-cost airline) & 4 \\
\hline CEO of Star Alliance & 3 \\
\hline Chair of Climate Change Taskforce & 3 \\
\hline CEO of International Air Transport Association (IATA) & 2 \\
\hline Director of Greenpeace & 2 \\
\hline CEO of International Civil Aviation Organization (ICAO) & 1 \\
\hline President of a developing country (e.g. Kenya) & 1 \\
\hline
\end{tabular}

German Advisory Council on Global Change, 2002) and energy or carbon budgets (e.g. Carlsson-Kanyama \& Linden, 1999; Spreng, 2005).

To stimulate a discussion with a wide range of perspectives, tourists were asked to choose pre-defined roles (from a show card) and provide arguments in favour or against any of the scenarios from this particular perspective. Each role was explained by a few key points to help participants identify with their role. The role play was intended to allow participants to bring forward arguments that they might not have felt comfortable with in their personal role and thereby overcome the possible bias of providing 'desirable' answers. The most popular roles were those directly related to tourism and the 'President of the World Wildlife Fund for Nature' (Table 1). Tourists were asked to adopt their role, i.e. act as they assumed their respective character would do. Tourists seemed not to have any difficulties with the role play and were very enthusiastic about it.

\section{General discussion}

The transition between role play and discussion required no facilitation, because at the end of the role-play most participants expressed the desire to present their own opinion. The discussion followed a loose schedule to cover the three policy scenarios, the relative importance of climate change and the idea of carbon offsetting (via forest sinks ${ }^{4}$ ) as a means to reduce the net impact of air travel.

In total, 32 tourists participated in the focus group meetings. All were independent travellers and most were on extended round-the-world trips, i.e. most participants were experienced air travellers. There were 19 male and 13 female participants with a good spread across age groups. Many were in their 20s or $30 \mathrm{~s}$, reflecting the venue of the sessions, but several were in their $50 \mathrm{~s}$ or $60 \mathrm{~s}$. Most had university degrees or were about to start university education. More than half of the participants came from the UK and Ireland, the rest came from 
Australia (3), United States (4), Czech Republic, Switzerland, Germany, Spain, Belgium and Brazil (1 each).

\section{Results}

The environmental implications of long distance holidays and tourists' interaction with mitigation policies can be usefully discussed in a framework of the internal and external factors that ultimately influence behaviour (Jackson, 2005). Influencing factors that are internal to the individual include attitudes, values, habits and personal norms; examples of external factors are regulations, structural incentives or barriers and social factors.

\section{Internal factors}

The different aspects of a tourist's internal factors and their inter-relationships as expressed by tourists in this research are visualised in Figure 1. Knowledge of climate change (i.e. a scientific understanding) or other environmental impacts plays an important role in relation to tourists' awareness and perception of climate change, as well as how they assess their individual responsibility. Recognising knowledge gaps or lack of awareness, tourists expressed the need for more information. Responsibility seems to differ for the individual as a 'tourist' or a general member of society. The latter seemed to be influenced by norms, while the responsibility as a tourist was mainly discussed in relation to the barriers that limit tourists' behaviour. Values or attitudes were not specifically explored in this research but are likely to play an important role as well.

\section{Knowledge, awareness and information}

When tourists were engaged in a discussion on climate change, it became evident that their knowledge was very generic, and links between own behaviour (i.e. air travel) and climate impact were rarely made. The focus group research, however, highlighted very different levels of expertise across the various focus group meetings. Participants enjoyed the climate change quiz and often expressed amazement about the correct answers. The following excerpt from

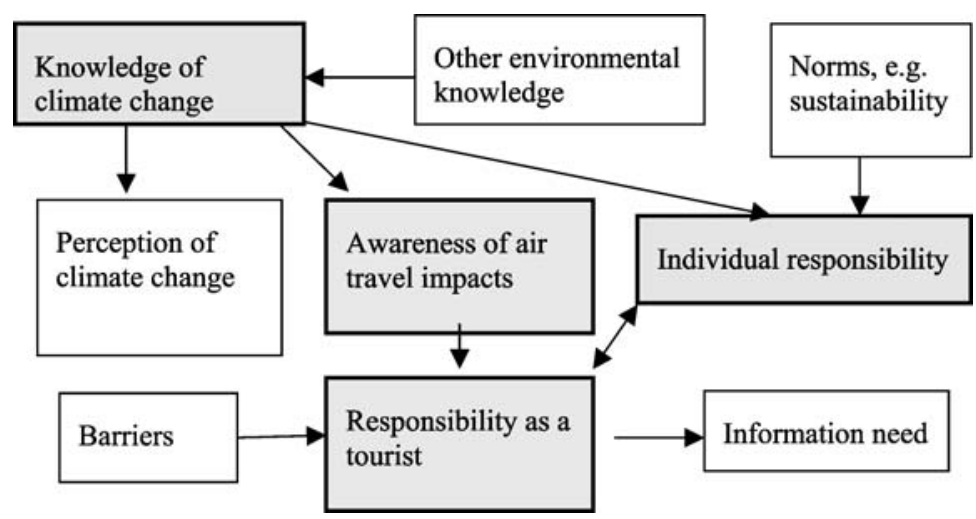

Figure 1 Internal factors: knowledge, perception and awareness of climate change and how they relate to the tourists' perception of responsibility (key factors are highlighted) 
one meeting's role play involving the facilitator, and the imaginary 'President of WWF' and 'CEO of Star Alliance' highlights the lack of deeper understanding.

\section{Facilitator:}

\section{Imaginary President of WWF: Facilitator:}

Imaginary CEO Star Alliance: Imaginary President of WWF: Imaginary CEO Star Alliance: Imaginary President of WWF:
The WWF must be an expert in the question whether climate change will do any harm to our national parks.

Of course, yeah definitely. Will it?

No.

Yes! Climate change?

No. Not to the parks in Kenya.

I have no idea. . . (all laugh).

In the focus group discussion, participants brought forward a wide range of aspects relating to climate change, for example, vapour trails from aeroplanes, unusual weather patterns in the last years, melting ice caps, uncertainty about whether changes can be attributed to human activities and the use of renewable energy sources. Mostly, the arguments were correct in principle but were diffused with inaccuracies, for example 'In Holland, there are already cars running on water.' Participants also referred to the Kyoto Protocol, and the concept of external costs from air travel. When asked if tourists knew of ways that GHG emissions could be mitigated, the majority of respondents could not answer, and only few tourists had heard of the terms carbon 'compensation' or 'offsetting'. It seemed doubtful that tourists were able to make a useful connection between forests and air travel, as already observed by Becken (2004). More often, reforestation or tree planting was associated with local conservation projects and the immediate and local benefits of landscaping and biodiversity. Some thought that the effect of air travel might be to kill trees.

Despite the lack of specific knowledge relating to tourists' travel, the participants of the different focus groups (both in the role play and the discussion) perceived that climate change 'is a massive problem' and 'happening now.' Some saw climate change 'at the top of our list' in terms of global problems, whereas some noted that other social or environmental problems might be more pressing, for example, alleviating poverty in third world countries. No research participant made a link between those global problems or argued that mitigating climate change could be an important part of decreasing poverty.

Focus group participants showed a low awareness of air travel's climate change impacts; even though tourists may hold some knowledge about it (see also Ungar, 2000, in Corbett et al., 2002). Awareness relates to knowledge and perception but refers specifically to the individual consciousness about specific facts. Some of the focus group participants explained their low awareness by a lack of knowledge and information, for example 'I didn't know half of the facts there, about how much tonnes of carbon dioxide I dumped on my way here. . . And I think if people were more educated, they'd feel the need more [. . . ] to actually try and make up for that.' A couple admitted that when they planned their trip 'In hindsight, after hearing all this tonight, we should have probably looked for [a more fuel-efficient car]. . . it would have probably saved us a fortune in petrol money.' The need for information was expressed in the discussion part of the focus group research, where reference was made to the need for both 
governments and scientists to provide more information to the general public. These comments also confirm the educational value of focus groups.

\section{Individual responsibility}

A small number of tourists showed that they did not feel accountable for the GHG emissions caused by their air travel. Mitigation of aircraft impacts was not seen as a personal responsibility. Some made jokes about possible transport alternatives such as swimming or sailing to New Zealand. This kind of humour could be interpreted as a defence mechanism to sudden internal dissonance.

The structure of the focus group meeting (using three phases) allowed tourists to reflect longer and consider their personal responsibility. In some cases, tourists had at first not felt responsible because they were not even aware of their impacts, noting 'now that I know this I feel guilty.' Following some discussion, tourists generally agreed 'it is everybody's responsibility.' Diverting into generalised responsibility (e.g. 'We need people to travel less!'), rather than specifically referring to oneself was common. These statements were often informed by reference to a wider sustainability paradigm, often in relation to future generations or anthropocentric versus biocentric perspectives (e.g. Imaginary 'Director of Greenpeace': 'You are interested in the people rather than the world that they actually inhabit?').

When playing a 'tourist' in the role play, participants expressed possible 'tourist views' that were otherwise not presented in the general discussion, for example, 'I don't really mind if emissions go up.' In those roles, tourists also admitted freely that they would opt for voluntary policies, because then they could continue their present lifestyle and travel behaviour. One 'tourist with a low budget' in the role play pointed out 'I will go for the voluntary initiatives, because otherwise I am going to pay so much more to travel.' Travel costs are important in tourists' travel decisions, whereas environmental factors are usually not considered. Airlines in particular are much more likely to be chosen based on price, and may be also based on routing.

Tourists in the general focus group discussion confirmed the views expressed in the role play, although in somewhat less explicit statements. On the other hand, they also indicated that increased airfares would not prevent them from travelling and that 'all [people] would fly anyway even if tickets would be more expensive.' This was somewhat contradictory to statements made about their preference for cheap flights. They agreed that schemes would need to be very simple, for example, one participant in the focus group discussion elaborated on how to pay for carbon offsetting: 'You could do it at the point of payment, you could just click [on the Internet], not think about it, pay it [... ]. It is like picking sweets at the supermarket checkout.'

\section{External factors}

The main elements in the tourist's external environment and relationships as identified by tourists in this research are shown in Figure 2. Governments - informed by scientists - are charged with implementing and monitoring climate policies, and overcoming barriers. Airlines and the tourism industry were mainly seen as being economically affected by climate change policies, 


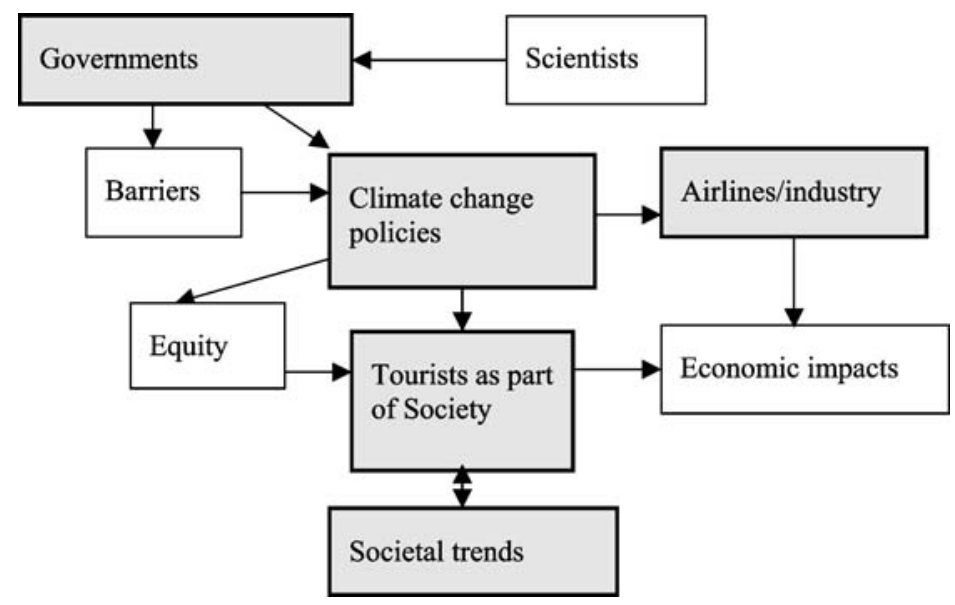

Figure 2 Main aspects of the external environment relating to climate change policies for air travel as discussed by tourists (key factors are highlighted)

in particular, low-cost airlines. Tourists saw themselves affected by the three suggested policy scenarios, which were also seen to impact on global economic growth and the distribution of wealth (i.e. equity). Tourists see themselves in the context of wider societal trends, and the totality of influencing factors has to be seen as an interaction between those displayed in Figures 1 and 2 .

\section{Overview of the three policy scenarios}

The role play in the focus group yielded useful information on how tourists interacted with the three suggested policy scenarios. In their various roles, participants were able to bring forward a range of valid arguments (Table 2). Voluntary initiatives were favoured by those in 'tourist' and 'industry' roles, largely

Table 2 Arguments in favour or against the three different policy scenarios discussed in the role play

\begin{tabular}{||l|l|l||}
\hline Scenario & Positive aspects & Negative aspects \\
\hline $\begin{array}{l}\text { Voluntary } \\
\text { initiatives }\end{array}$ & $\begin{array}{l}\text { Allows airlines flexibility in } \\
\text { mitigation initiatives. Allows } \\
\text { tourists to travel. }\end{array}$ & $\begin{array}{l}\text { Little effect. Unfair when only few par- } \\
\text { ticipate. }\end{array}$ \\
\hline $\begin{array}{l}\text { Air travel } \\
\text { taxes }\end{array}$ & $\begin{array}{l}\text { Internalises climate costs. Re- } \\
\text { duces air travel and there- } \\
\text { fore emissions. Same treat- } \\
\text { ment as for other transport } \\
\text { modes. Easy implementation. }\end{array}$ & $\begin{array}{l}\text { Affects less-wealthy people. Reduces } \\
\text { tourism income in developing coun- } \\
\text { tries. Reduces profits of airlines and } \\
\text { therefore investment into new tech- } \\
\text { nologies. Ineffective incentive for air- } \\
\text { lines to reduce emissions. Loss of jobs } \\
\text { in the airline and tourism industry. }\end{array}$ \\
\hline $\begin{array}{l}\text { Carbon } \\
\text { budget }\end{array}$ & $\begin{array}{l}\text { Effective in reducing global } \\
\text { emissions. Trading emissions } \\
\text { provide an income for de- } \\
\text { veloping countries. Option to } \\
\text { save budget or trade allows } \\
\text { tourists to travel. }\end{array}$ & $\begin{array}{l}\text { Limits freedom to travel. Monitoring } \\
\text { challenging. Reduces profits of air- } \\
\text { lines and therefore investment into } \\
\text { new technologies. Loss of jobs in the } \\
\text { airline and tourism industry. }\end{array}$ \\
\hline
\end{tabular}


because these would not affect the status quo of affordable and unimpeded travel. On the other hand, it was argued - largely by those in 'environmental' roles - that voluntary initiatives will not result in any GHG reductions ('Voluntary initiatives don't work. Full stop'; Imaginary 'Chair of the Climate Change Taskforce'), and one tourist in the focus group discussion exclaimed: 'It has been voluntary for the last 30 years!'. Voluntary initiatives were also seen as being unfair if only a minority participated. Scepticism was evident in relation to the usefulness of carbon sinks and tree planting.

Global air travel taxes were seen as a good compromise between limiting travel and business and achieving reductions in GHG emissions; taxes would also be easy to implement. Global air travel taxes would reduce demand for travel, especially from less-wealthy people. The resulting discrimination by wealth was considered a major drawback of an air travel tax. The economic impacts of air travel taxes would affect the tourism industry as well as destinations, which tourists found particularly concerning in the case of developing countries. The potential loss of jobs in the tourism industry was noted by several focus group participants, for example, by the imaginary 'CEO of Ryanair'. An air travel tax would be a blunt policy instrument that would not necessarily lead to innovation in the airline industry to reduce emissions. Moreover, several participants in the focus group discussion doubted whether a tax would be effective in reducing emissions. The comparison was made between car and air travel, where high taxes on petrol do not necessarily lead to less use. Some tourists commented, however, that taxes do provide sufficient incentive to change behaviour.

The carbon budget concept was identified as the most effective policy to reduce global emissions. It would be possible to save one's carbon budget and use it for exceptional items, for example, a long-distance flight. Also, trading was suggested as an opportunity to redirect money from wealthy to poorer people. The carbon budget was clearly preferred by those with a strong interest in reducing global emissions (e.g. imaginary 'Chair of the Climate Change Taskforce'), but opposed by those who are involved in travel (e.g. the 'tourist' and 'airline' roles). Implementation and monitoring were seen as major impediments to introducing this policy. Several participants commented that an 'energy police' or 'state of supervision' would be needed in this scenario. One focus group participant noted that emission trading already takes place under the Kyoto Protocol and that technology should make it possible to account for, and trade, small individual budgets.

\section{Other actors}

Responsibility to address climate change impacts from air travel was largely seen to lie with governments or international organisations (e.g. the United Nations). Governments were specifically mentioned when focus group participants recognised the inefficacy of voluntary initiatives ('It has to come down to governments and international organisations to force us to do that, else it just won't happen'). Those in 'environmental' roles in the role play accused governments of not doing enough, both in terms of regulation, enforcement and information. The imaginary 'Chair of the Climate Change Taskforce' commented that he 'would like to see more pro-activism, governments will actually inform the people more [...] to do something for the climate and the world.' At the same 
time, there was serious distrust of governments, in particular, relating to taxes and what the money collected is used for, and as one imaginary 'tourist with a low budget' pointed out: 'Governments are supposed to act on behalf of the people but very rarely do that.' Those in industry roles, for example, the imaginary 'CEO of Touristik Union International' (TUI), reinforced that they would not trust the government and give them money.

A similarly contradictory attitude could be found in relation to airlines. Tourists expressed the view that GHG emissions are to some extent the responsibility of the airline, which as a consequence should pay the tax (rather than passing it on to the consumer). Airlines were also suggested as a source for more information; at present, airlines rarely inform their customers about environmental performance. On the other hand, there was mistrust in the airline industry, because their main objective is to make profit. The importance of the economic bottom line was highlighted by the imaginary 'CEO of TUI': 'I sell vacations to everyone, and whatever you guys make out of it, I'll make money. Doesn't matter, I will find a way.' Attempts by the airline industry to be involved in mitigation initiatives were sometimes interpreted as green-washing, money-making or advertising. Tourists perceived a power discrepancy between themselves or environmental organisations, and the industry, as exemplified in the following dialogue:

\section{Imaginary ‘CEO Ryanair’:}

You are gonna put me out of business altogether. You wrecked my company!

Imaginary 'Director Greenpeace': Well ... you are at the top. . . [laughter]

Scientists were mentioned only a few times and their role was mainly seen in informing the governments and 'sorting out the problem' in some undefined way ('I think the scientists should do something about it'). Scientists were also referred to when tourists talked about technological improvements to aircraft, or alternative energy sources. These were, however, more commonly considered to be the responsibility of airlines.

Tourists discussed the delicate balance between economic growth associated with tourism and impacts on the climate as a result of air travel. Those in support of tourism in the role play (e.g. 'tourists' and 'airlines') argued that tourists bring a lot of money into poorer countries, and the example of tourism recovery in Thailand after the Tsunami was used to illustrate how important it is that people continue to travel ('These air travel taxes are just a way of keeping developing countries undeveloped'). This argument was also used to justify why holiday travel should not be penalised, whereas business travel could be regulated. The imaginary 'President of Kenya' argued in one focus group role play that the money collected through a carbon charge could be redistributed to developing countries (as currently done in France). Similarly, carbon budgets and resulting trading would offer an opportunity to developing countries to raise money from carbon surplus.

Occasional reference was made in the focus group meetings to the fact that some of the largest emitters have not signed the Kyoto Protocol and that the introduction of climate change policies could lead to unfair treatment among countries. The development of China and its growing demand for energy was 
also mentioned, and some tourists questioned the global relevance of air travel compared to those emission sources.

Another commonly discussed topic was that mitigation policies should differentiate between different types of travel or travellers. Particular reference was made to business travel, as business travellers were perceived to contribute substantially to GHG emissions (reference was made to telecommunication as an alternative) and suggested that business travel should be taxed more than holiday travel. One tourist suggested that short-distance flights be taxed more than longer flights to induce some modal shift to less carbon-intensive transport modes. Tourists also seemed to make a difference between 'legitimate holidays' (like the current one in New Zealand) and 'dispensable' trips, such as short breaks or shopping trips.

\section{Wider societal context}

Tourists in this research perceived environmental responsibility differently in the holiday context compared with the everyday situation at home. When planning holidays, other factors (e.g. cost) are more important, and the positive anticipation of a holiday is rarely compromised by considering the negative effects of one's travel ('You have gone away to have a break from your daily routine'). Tourists noted that GHG mitigation should focus on the home environment rather than on travel, which tourists often perceived to be an extraordinary and therefore negligible contribution to overall emissions. Tourists felt that it is easier to take personal action at a local level rather than globally, for example, by minimising waste. Often respondents mentioned that they belonged to environmental organisations (e.g. Greenpeace) or supported conservation projects, suggesting that they are already taking sufficient action to protect the environment; a denial mechanism already identified by Stoll-Kleemann et al. (2001). In relation to carbon sequestration through forest regeneration, tourists also preferred to be active in their home country: 'I am more likely to [plant a tree] at home', although a few tourists commented that they would enjoy the experience of planting a tree at their holiday destination.

Flying is increasingly accepted as an integral part of people's lives, and 'getting to know the world' was an explicitly expressed aspiration by participants in this research. Tourists admitted that the freedom to travel is a much valued good that they do not wish to see compromised. As a result, the scenario of a carbon budget was not favoured: 'I don't want to limit any of my travels, I certainly would not go for scenario three.' Freedom of travel was seen as an important prerequisite to maintaining a global connectedness (see also Shaw \& Thomas, 2006) that has been fuelled by modern communication technology. In the case of New Zealand, air travel was also seen as an indispensable means to keep in contact with family members living in New Zealand (27\% of tourists to New Zealand come to visit friends or relatives; Tourism Research Council, 2005).

Several of the focus group discussions centred around aspects of hypermobility, for example, tourists reported that 'people are in a rush, they have to go places, they are not conscious of anyone, let alone the environment.' Tourists stated that everyone wants to get everywhere as quickly as possible, and 'the airlines are assisting us in doing it.' The popularity of low-cost carriers was discussed heavily in most focus group meetings, and most tourists were able 
to report about their personal experience with cheap flights. Tourists are well aware that air travel is too cheap (i.e. not accounting for external costs), but the benefit they receive from travel outweighs possible concerns. The concept of a carbon budget offers the opportunity to make individual trade-offs between using the carbon budget and benefit gained from a particular use. As observed by Lorenzoni and Pidgeon (2005), people phrase their discourse around personal or societal benefits rather than negative impacts. Reference was made to Western Societies' lifestyle in general and the fact that we are 'selfish', 'instant people' who will not renounce our luxuries until we 'are hit over the head.' The tragedy-of-the-commons dilemma (see also Stoll-Kleemann et al., 2001) was epitomised by a tourist who stated: 'The unfortunate thing is that we want to see the world. . . before we finish it up.'

\section{Conclusion}

This research explored tourists' knowledge and perception of climate change impacts related to air travel, their perception of individual responsibility and their engagement with three possible policies. The research has to be interpreted in the context of independent tourists to long-distance (nature-tourism) destinations and the design of the focus group (i.e. information and scenario choices provided), and the findings do not allow wider conclusions about tourists in general.

The three policy options discussed in the focus group research involved voluntary initiatives, a global air travel charge and a carbon budget. The trade-off between actual reductions in GHG emissions from air travel and political and practical feasibility was discussed, and the global air travel tax emerged as a realistic compromise between restricting travel and achieving emissions reduction. The analysis of both internal and external factors highlighted several challenges when trying to reduce the contribution of air travel to climate change. These relate to the lack of knowledge and awareness, the way tourists perceived their responsibility for global environmental impacts when travelling and the wider societal context at a time when air travel is a means to provide economic benefit, cultural exchange, personal development and status.

Tourists in this research had little specific knowledge about how air travel affects the global climate change. Many tourists who participated in this research expressed a wish for more information, as this would increase their awareness when making travel-related decisions. Having more information on environmental impacts could lead to pro-environmental decisionmaking, and in an earlier study on global warming, O'Connor et al. (1999) confirmed that knowledge was the most important precursor for action. In the context of sustainable consumption, and in particular in relation to global problems, however, it has been found that boosting the levels of information and awareness often only increases the level of helplessness and lack of individual control, and therefore could result in reduced individual action (Jackson, 2005). The fact that tourists in the focus group research were able to discuss the three policy scenarios when given some initial information highlights that their knowledge is sufficient to understand the issue of climate change and air travel. This research shows that information is important, but probably will not be sufficient on its own to induce behavioural change in relation to air travel. 
When discussing individual responsibility for GHG emissions, tourists distinguished between their travel (something extraordinary) and their everyday life. At home, they argued, they were more likely to consider environmental factors in their decisionmaking, for example, purchasing organic food. This confirms Spaargaren's (2003) model that people apply different principles and rules to various segments of their lifestyle. The possibly lower level of 'green provisioning' (e.g. environmentally friendly alternatives) in the travel industry and lack of 'environmental heuristics' on the part of tourists (Spaargaren, 2003: 690) could also explain why people are less concerned about the environment when on holiday. Gössling et al. (2007) noted tourists' greater awareness of local environmental impacts (e.g. littering) compared with global climate change.

Tourists generally refused the mitigation option of reducing the number of flights and travel distance. The value of freedom to travel is firmly established in the minds of those frequently-global-travelling tourists who participated in this research. The public discourse on the social and economic benefits associated with air travel (Gössling \& Peeters, 2007) legitimises tourists' desire to participate in global mobility. Limiting travel would counteract wider societal trends of affordable travel, an increasing individual mobility and a global connectedness, recently denominated as 'hypermobility' (Adams, 2000). Indicators of hypermobility (e.g. 'global citizenship', global networks, use of electronic communication and multiple short trips) have been identified among tourists in this research. While some tourists described the trends as a lock-in situation that they are not able to influence, other tourists expressed that the desire of 'getting to know the world' is simply part of their personal identity. These findings show that tourists' engagement in international air travel goes well beyond individual dimensions of functionality (e.g. relaxation), attitudes and values, but that participation in global travel has a high symbolic meaning and therefore is a fundamental part of an individual's positioning in society. Given the great (perceived) benefit from air travel, it seems unlikely that tourists would voluntarily support mitigation policies that would restrict their ability to travel.

While tourists stated that air travel has become an integral part of their lives, they also knew that this privilege conflicts with the socially desirable behaviour of being a sustainable citizen. When tourists reported their active involvement in local pro-environmental behaviour, it became clear that the paradigm of sustainability has gained traction among the general public. Concerns about future generations were also raised in the context of global climate change. The psychological discrepancy (Higgins, 1987, in Jackson, 2005) that results from tourists' actual behaviour and their perception of what one 'ought' to do seemed insufficiently strong to induce behavioural change when it comes to air travel. When confronted with the negative effects of air travel on the climate, tourists showed signs of discomfort and dissonance (i.e. inconsistencies between attitudes and behaviour [Festinger, 1957]). As discussed by Stoll-Kleemann et al. (2001), people seek to dissolve dissonance by denial, as one among other possible psychological defence mechanisms. While tourists in this research did not deny that climate change is happening, they showed denial by seeking scapegoats (e.g. airlines, business travellers, countries that have not ratified the Kyoto Protocol), by indulging purposely in detrimental behaviour (e.g. flying as long as they can - free-riding), and by deferring personal responsibility. The latter form of 
denial manifested, for example, in tourists displacing personal responsibility for climatic impacts from the holiday sphere to tourists' lives at home (where possibly other denial strategies apply).

Denial can be observed on an individual level, but there are also situations of collective denial. This phenomenon has been described as the 'passive bystander' (Cohen, 2001), whereby individuals await collective action rather than feeling personally responsible. The dilemma of air travel and global climate change is an excellent example of collective denial, where everyone waits for someone else to do something. This research showed that there is 'latent' support for mitigation policies relating to aviation, and tourists are - when prompted - aware of the fact that air travel is 'too cheap'. This result is in accordance with recent public consultation on this issue in the European Union (European Commission, 2005). In other words, tourists are prepared to accept measures necessary to ensure the wellbeing of our planet and societies, but they take personal benefit from the current setup for as long as they can. At present, little can be expected from tourists in terms of voluntary initiatives and proactivism to address the global impact of air travel. Marshall (2001) argued such a situation can only be overcome if people are 'confronted by emotionally charged activities; debate, protest, and meaningful, visible alternatives'. This research indicated that governments should take a lead role in this, supported by scientists and working together with airlines. A social movement such as this will also require renegotiating the current trends towards hypermobility and the positively biased social representation of air travel in particular. Initiatives need to take explicit account of the fact that tourists' behaviour cannot be reduced to individual decisionmaking, but has to be dealt with in the context of the society tourists live in.

\section{Acknowledgements}

The author thanks Axel Reiser for organising and facilitating the focus group research. The support of the Youth Hostel Association (in particular, Mardi Neumann) and Christchurch International Airport has made this research possible and is greatly appreciated. The author also thanks James Lennox, Phil Hart, Maurice Marquart and Paul Peeters for comments on drafts of this paper. This research is part of a larger project on tourism's GHG emissions funded by the New Zealand Foundation for Research, Science and Technology.

\section{Correspondence}

Any correspondence should be directed to Susanne Becken, Lincoln University, P.O. Box 84, Lincoln 7647, Canterbury, New Zealand (beckens@ lincoln.ac.nz).

\section{Notes}

1. The contribution of air travel to global emissions is expected to increase substantially as a result of its forecast growth rates. In the case of the UK, emissions from international air travel will make up 22, 39 or $67 \%$ of the national $\mathrm{CO}_{2}$ budget in 2050, depending on different growth rates of air travel at 3, 4 or $5 \%$ (Lee et al., 2005). Large uncertainty is associated with climate impacts resulting from non- $\mathrm{CO}_{2}$ emissions, in 
particular, those related to water vapour, contrails and cirrus clouds. A recent study on radiative forcing by Sausen et al. (2005) reported much lower radiative forcing from contrails compared with the earlier estimates by the Intergovenmental Panel on Climate Change (IPCC); however, the study also points out that the effect of induced cirrus clouds could be much larger than anticipated. The authors conceded that knowledge of aircraft-induced clouds is still very poor.

2. The reason for the exclusion of emissions from the Kyoto Protocol lies in the international nature of aviation and the long history of special treatment of fuel used in international transport, dating back to the Chicago Convention of 1944 and a 1950 resolution by the International Civil Aviation Organisation (ICAO) to exempt fuel for international air travel from taxation. This is now incorporated in about 3000 different bilateral air service agreements between states, which are legally binding (Meijers, 2005).

3. The European Union discussed the inclusion of aviation into its Emission Trading Scheme (ETS), which would be the first time that aviation is regulated in terms of its GHG emissions. The two key features of an ETS are that there is a price on carbon and that the right to emit is constrained. These two elements are represented in the policy options presented to tourists, namely a carbon charge (Scenario 2) and a carbon budget (Scenario 3). It was decided to present these options separately because the idea of an ETS might be too complex for tourists and also because the separation into two scenarios allowed assessment of each feature individually.

4. Carbon sequestration through reforestation of native forest is a preferred policy in New Zealand given the availability of space and strong commitment to biodiversity. Schemes are already in place to allocate marginal farmland as carbon sinks, funded by carbon credits. Landcare Research operates various carbon calculators - among others, one for tourism - that allow individuals or companies to offset their emissions in this way. The New Zealand schemes build on sequestration times of 300 years (lifetime of native forests) and incorporate contingencies for disruptions to the sequestration process as a result of fires, pests and other occurrences.

\section{References}

Adams, J. (2000) The social implications of hypermobility. Report for the Economic Cooperation and Development. http://www.oecd.org/env/docs/epocppct993.pdf. Accessed 20.01.05.

Barbour, R. (1995) Using focus groups in general practice research. Family Practice 12 (3), $328-334$.

Becken, S. (2002) Analysing international tourist flows to estimate energy use associated with air travel. Journal of Sustainable Tourism 10 (2), 114-131.

Becken, S. (2004) How tourists and tourism experts perceive climate change and forest carbon sinks. Journal of Sustainable Tourism 12 (4), 332-345.

Brons, M., Pels, E., Nijkamp, P. and Rietveld, P. (2002) Price elasticities of demand for passenger air travel: A meta-analysis. Journal of Air Transport Management 8, 165175.

Carlsson, F. and Hammar, H. (2002) Incentive-based regulation of $\mathrm{CO}_{2}$ emissions from international aviation. Journal of Air Transport Management 8 (6), 365-372.

Carlsson-Kanyama, A. and Linden, A.L. (1999) Travel patterns and environmental effects now and in the future: Implications of differences in energy consumption among socioeconomic groups. Ecological Economics 30, 405-417.

Cohen, S. (2001) States of Denial. Knowing about Atrocities and Suffering. Cambridge: Polity.

Corbett, J.B., Durfee, J.L., Gunn, R.D., Krakowjak, K.M. and Nellermoe, J.T. (2002) Testing public (un)-certainty of science: Media representations of global warming. In 7th International Conference on Public Communications of Science and Technology, Capetown, South Africa, 5 December.

European Commission (2005) Reducing the climate change impact of aviation. Report on the Public Consultation March-May 2005. http://europa.eu.int/comm/environment/ climat/aviation_en.htm. Accessed 01.08.05. 
Fairweather, J.R., Maslin, C. and Simmons, D.G. (2005) Environmental values and response to ecolabels among international visitors to New Zealand. Journal of Sustainable Tourism 13 (1), 82-98.

Festinger, L. (1957) A Theory of Cognitive Dissonance. Stanford, CA: Stanford University Press.

German Advisory Council on Global Change (2002) Charging the use of Global Commons, Berlin. http://www.wbgu.de/wbgu_sn2002_engl.html. Accessed 20.11.04.

Gibbs, A. (1997) Focus groups. Social Research Update, Winter (19). http://www. soc.surrey.ac.uk/sru/SRU 19.html.

Gillen, D., Morrison, W. and Stewart, C. (2005) Air travel demand elasticities: Concepts, issues and measurements. Final Report. Department of Finance, Canada. http://www.fin.gc.ca/consultresp/Airtravel/airtravStdy_e.html. Accessed 20.02.06.

Goss, J.D. and Leinbach, T.R. (1996) Focus groups as alternative research practice. Area $28(2), 115-123$.

Gössling, S., Bredberg, M., Randow, A., Svensson, P. and Swedlin, E. (2006) Tourists' perceptions of climate change: A study of international tourists in Zanzibar. Current Issues in Tourism 9 (4\&5), 419-435.

Gössling, S. and Peeters, P. (2007) 'It does not harm the environment!' - An analysis of industry discourses on tourism, air travel and the environment. Journal of Sustainable Tourism 15 (4), 402-417.

Henry, A.D. (2000) Public perceptions of global warming. Human Ecology Review 7 (1), 25-30.

International Civil Aviation Organisation (2004) Assembly - 35th Session, Executive Committee, Draft text for the report on Agenda Item 15. A35-WF/314, EX/116.

Jackson, T. (2005) Motivating Sustainable Consumption. A Review of Evidence on Consumer Behaviour and Behavioural Change. Guildford: Sustainable Development Research Network, University of Surrey.

Kasemir, B., Dahinden, U., Swartling, A.G., Schuele, R., Tabara, D. and Jaeger, C.C. (2000a) Citizens perspectives on climate change and energy use. Global Environmental Change 10 (3), 169-184.

Kasemir, B., Schibli, D., Stoll-Kleemann, S. and Jaeger, C.C. (2000b) Involving the public in climate change decisions. Environment 42 (3), 32-42.

Kempton, W. (1991) Lay perspectives on global climate change. Global Environmental Change 1 (3), 183-208.

Kitzinger, J. and Barbour, R.S. (1999) The challenge and promise of focus groups. In R.S. Barbour and J. Kitzinger (eds) Developing Focus Group Research: Politics, Theory and Practice (pp. 1-20). London: Sage.

Lee, D.S., Lim, L.L. and Raper, S.C. (2005) The role of aviation emissions in climate stabilization scenarios. In Poster at Avoiding Dangerous Climate Change Conference, Exeter, UK, 1-3 February.

Lorenzoni, I. and Pidgeon, N. (2005) Defining dangers of climate change and individual behaviour: Closing the gap. In Poster at Avoiding Dangerous Climate Change Conference, Exeter, UK, 1-3 February.

Marshall, G. (2001) The psychology of denial: Our failure to act against climate change. The Ecologist. http://www.ecoglobe.ch/motivation/e/clim2922.htm.

McDaniels, T., Axelrod, L.J. and Slovic, P. (1996) Perceived ecological risks of global change. Global Environmental Change 6 (2), 159-171.

Meijers, D. (2005) Tax flight. An investigation into the origins and developments of the exemption for various kinds of taxation of international aviation. In International Centre for Integrative Studies (ICIS) Working Paper: IO5-E001.

Morgan, D.L. and Kreuger, R.A. (1993) When to use focus groups and why. In D.L. Morgan (ed.) Successful Focus Groups. London: Sage.

O'Connor, R.E., Bord, R.J. and Fisher, A. (1999) Risk perceptions, general environmental beliefs, and willingness to address climate change. Risk Analysis 19 (3), 461471.

Penner, J., Lister, D., Griggs, D., Dokken, D. and McFarland, M. (eds) (1999) Aviation and the Global Atmosphere. In A Special Report of IPCC Working Groups I and III. Published 
for the Intergovernmental Panel on Climate Change. Cambridge: Cambridge University Press.

Sausen, R., Isaksen, I., Grewe, V., Hauglustaine, D., Lee, D., Myhre, G., Koehler, M., Pitari, G., Schumann, U., Stordal, F. and Zerefos, C. (2005) Aviation radiative forcing in 2000: An update on IPCC (1999). Meteorologische Zeitschrift 14 (4), 555-561.

Shaw, S. and Thomas, C. (2006) Social and cultural dimensions of air travel demand: Hyper-mobility in the UK? Journal of Sustainable Tourism, 14 (2), 209-215.

Spaargaren, G. (2003) Sustainable consumption: A theoretical and environmental policy perspective. Society and Natural Resources 16, 687-701.

Spreng, D. (2005) Distribution of energy consumption and the $2000 \mathrm{~W} /$ capita target. Energy Policy 33, 1905-1911.

Stoll-Kleemann, S., O'Riordan, T. and Jaeger, C.C. (2001) The psychology of denial concerning climate mitigation measures: Evidence from Swiss focus groups. Global Environmental Change 11, 107-117.

Tourism Research Council (2005) International Visitor Survey. http://www.trcnz.govt.nz. Accessed 20.06.05.

Weeden, C. (2005) A qualitative approach to the ethical consumer: The use of focus groups for cognitive consumer research in tourism. In B. Ritchie, P. Burns and C. Palmer (eds) Tourism Research Methods. Integrating Theory with Practice. Wallingford: CABI.

Wit, R., Boon, B., van Velzen, A., Cames, M., Heuber, O. and Lee, D. (2005) Giving wings to emission trading. Inclusion of aviation under the European emission trading system (ETS): Design and impacts, Summary of draft final report. http://www.ce.nl. Accessed 02.06.2005.

Zehr, S. (2000) Public representations of scientific uncertainty about global climate change. Understanding of Science 9 (2), 85-103. 